\title{
СУБЪЕКТИВИЗМ И РЕВОЛЮЦИЯ В ВЕК ИНФОРМАЦИОННЫХ ТЕХНОЛОГИЙ
}

\author{
Савченко В. А.
}

Ускорение прочессов глобализачии способствовало росту числа насильственных способов смены политических форм и режимов правления в государствах. Мировые события последних десятилетий свидетельствуют, что традищионные научные подходы к изучению револючионных прочессов не только не могут в необходимой степени предоставить убедительный прогноз их развития, но и далеко не всегда в состоянии выявить причины их возникновения, особенно в условиях энергичного влияния информационных технологий. В статье предлагается вариант обоснования необходимости пересмотра инструментария исследования современных революционных проиессов.

Ключевье слова: революиия, пропаганда, агитация, оппозиция, А. Грамии, гегемония, цивилизационный разлом.

The accelerated globalization has contributed to increasing number of violent ways to change political forms and regimes of government in states. The events in the world in recent decades indicate that traditional scientific approaches to the study of revolutionary processes cannot make convincing predictions about their development, and besides, they are far from always able to identify the causes of their occurrence, especially in the conditions of vigorous influence of information technologies. The article proposes a possible justification of the need to revise the research tools of modern revolutionary processes.

Key words: revolution, propaganda, agitation, opposition, A. Gramsci, hegemony, civilizational rift.

Идея функционирования и развития социальных систем без революционных потрясений существует в настоящее время как недосягаемый идеал. Акты насильственной смены правящих группировок на постсоветском пространстве являются свидетельством того, что риск революции может возникнуть и реализоваться неожиданно, вопреки классическим теориям революций и зачастую косвенно касаясь экономического состояния конкретного социального образования, в том числе его отставания от соседних стран. В современных условиях очевидна возрастающая общественная потребность в переосмыслении сущности и содержания взаимоотношений «власть - народ». Могущество отдельных стран базируется на многих факторах. Один из них - способность восстанавливать состояние приемлемой устойчивости при внешних и внутренних возмущающих воздействиях, в ходе идеологического давления извне и местных протестных проявлений.

\footnotetext{
* Савченко Виктор Александрович - аспирант кафедры социологии и гуманитарных наук Государственного университета «Дубна». E-mail: moisey.1982@mail.ru.
}

Век глобализации 2/2020 85-94

DOI: $10.30884 / v g l o b / 2020.02 .08$ 
Именно поэтому важно провести корректный научный анализ предпосылок революций в современном мире, обратив особое внимание на обстоятельства, характерные для современной России. Общественный интерес и широкие дискуссии о безопасном будущем нашей страны включают в себя, в числе прочего, исследование совокупности факторов, приводящих к массовым беспорядкам и, далее, к возможной насильственной смене власти. Более того, актуальность проблематики обусловливается нестабильностью внешнеполитической обстановки, связанной с общемировыми кризисными явлениями. В таких условиях особо важными видятся вопросы обеспечения стабильного и безопасного развития российского общества. Крайне необходимо, чтобы социальная система отвечала параметрам, при которых реализуются принципиальные насущные запросы социума при сохранении стабильности и устойчивой тенденции к динамичному развитию.

После распада СССР Россия довольно быстро обрела немало черт, характерных для стран третьего мира, со значительным падением экономического развития, демографическим спадом, проблемами в области науки и образования. Подобные условия существования страны не только породили значительные препятствия для ее динамичного развития, но и создали серьезные угрозы ее жизнедеятельности. Среди институтов российской социальной системы, наиболее подверженных разрушительным процессам, оказались стратегические элементы, прежде всего политические, экономические и образовательные. Сам распад СССР многие исследователи квалифицируют как завершающий этап революции, о чем свидетельствует значительное число признаков. Это прежде всего соотнесение настоящего с будущим; доминирование коллективного начала и идеи социальной справедливости; построение нового общества на основе новой базовой культурной модели; подчеркивание возможности активного участия социальных групп в формировании нового социального и культурного порядка; универсалистская ориентация, отрицающая политические и национальные границы [Эйзенштадт 1999: 18].

Научный интерес к проблемам обеспечения социальной стабильности предполагает исследование предпосылок политических революций, в том числе изменение статуса России на международной арене в связи с распадом СССР. Самого пристального внимания заслуживают и проблемы, связанные с формированием установки на массовый протест как важнейший фактор дестабилизации социальной системы. Россия обладает немалыми возможностями и ресурсами для повышения своего статуса в мировом сообществе, но вследствие ряда факторов занимает лишь 62-е место из 80 по уровню жизни по состоянию на середину 2019 г. Подобная ситуация способствует повышению накала агрессии в отношении правящих элит, не заинтересованных в росте уровня жизни граждан и безразличных к необходимости адекватно реагировать на внешние угрозы. Все это увеличивает вероятность возникновения протестных акций, которые в ряде стран переросли в полномасштабные предреволюционные действия [Глобализация... 2014: 28-36].

Под революцией будем понимать процесс принципиальных политических, экономических и идеологических изменений в обществе, в который вовлечены массовые общественные движения и организации (прежде всего политические партии), сопровождающийся сменой существующих формы и режима, нередко путем насильственных действий. Во многом массовый характер отличает рево- 
люцию от других форм принудительной смены власти (заговоров, переворотов, свержений и т. п.). Понимание феномена массовости и является ключом к пониманию одного из предельных оснований революции.

Впервые вопрос о массовых формах протеста, которые способны привести к революции, был поднят еще Аристотелем. Он указал на два условия: когда люди не получают достойной доли влияния в деле государственного управления и когда отсутствует равноправие в материальном и статусном положении граждан [Аристотель 1983: 87]. При этом Аристотель особо подчеркивал, что реальное состояние дел менее важно, чем существующее в воображении людей [Там же: 114]. Многие его последователи, например Т. Гоббс, считали справедливым оказание почестей определенным группам людей, обладающих значительным объемом свободного времени [Гоббс 2001: 114], а также «бедность или недостаток того, что необходимо для поддержания достойной жизни» [Там же: 119]. Следует отметить, что суть понятия «достойная жизнь» заметно сместилась в сторону представлений о значительном увеличении потребления. Смысл же термина «революция» (в политическом аспекте) и в наши дни существует примерно в том же звучании, что и во времена Оливера Кромвеля (XVII в.). Впервые в сферу социальных и политических наук термин привнес Ф. Бэкон в 1720 г.

Изучение социальных событий, характерных для современного мира и имеющих признаки «революционности», требует нового ракурса рассмотрения.

Исследователями революционных процессов накоплен большой объем теоретического материала. Их рекомендации на практике дают неплохие результаты по прогнозированию и минимизации вероятности насильственных действий. Выявлены факторы, приводящие к формированию протестного потенциала, который с высокой степенью вероятности приведет к широкомасштабным протестам против сложившегося положения. Наиболее успешными считаются рекомендации, сориентированные на экономические явления и процессы. Со времен К. Маркса экономические предпосылки занимают важное место в процессе выбора вектора развития человеческого общества. Вместе с тем исследования последних десятилетий показали, что зависимости в этой области не столь прямолинейны, как выглядят в классических теориях.

В начале XX в. сложилось несколько научных школ, изучающих это социальное явление. Каждая школа имела свой особый взгляд на причины появления революционных движений, процесс их реализации и итоги. Особое внимание уделялось изучению детерминант возникновения революций. Остановимся на некоторых из них.

Первая научная школа по изучению революций появилась в 1925 г. Ее основал П. А. Сорокин. Действуя в парадигме Т. Гоббса, он усматривал появление стремления людей к революционным действиям в ущемленных природных инстинктах и приобретенных рефлексах, к которым относил пищеварительный рефлекс, инстинкт безопасности, собственнический инстинкт, половой рефлекс, импульс к соревновательности, творческой работе, приобретению разнообразного опыта и т. п. Сорокин отмечал неминуемость революции, когда подавление инстинктов и рефлексов у большого количества индивидов выпадает на время, для которого характерны слабость властей и их неспособность к подавлению силой революционных движений. Данная научная школа имеет название бихевиорист- 
ской (англ. Behavior - поведение) и причину возникновения революций видит в давлении снизу недовольной массы индивидов и неспособности властей сверху как удовлетворить их требования, так и эффективно применить в необходимой мере репрессивные меры [Сорокин 2005: 91].

Вторая школа, касаясь данной проблематики, рассматривает революционную мотивацию комплексно. Она связана не с подавлением инстинктов, а с болезненным синдромом сознания больших масс населения, которые считают сложившееся положение неприемлемым. Представители данного направления считают, что продуцирует революционные настроения не сама по себе нищета, а неполнота обеспечения людей необходимыми ресурсами. Именно это они воспринимают как крайнюю несправедливость.

Для определения степени готовности к протестным действиям используется понятие «относительная депривация». Это разница между тем, что люди имеют, и чего, по их мнению, заслуживают, то есть между растущими ожиданиями и возможностями. Появление этого болезненного синдрома имеет свои причины. Наиболее значимой теорией в рамках данной научной школы является теория Дж. Дейвиса, обосновывающая необходимость прерывания на определенном этапе параллельности роста благосостояния и ожиданий улучшения благосостояния в будущем. Данная школа рассматривает в качестве преобладающих психологические предпосылки возникновения революции [Дейвис 1967: 67-91].

Представители третьей научной школы, изучающей революционные процессы, отрицают главенствующую роль психологических факторов и отдают предпочтение факторам структурного несовершенства политических систем. Это возникающая напряженность между группами населения, различными политическими течениями во властных структурах, нарастание структурных противоречий в обществе. Оценивая состояние структуры социума, яркий представитель этой школы Т. Скочпол обнаружила во всех вышеперечисленных обстоятельствах острый политический и экономический кризис, обеспечивающий давление на правительство со стороны классовых структур и международного сообщества, который и играет в революционных процессах определяющую роль [Скочпол 2008: 49].

Четвертая школа рассматривает детерминанты возникновения революций только как политический процесс, как нарушение баланса власти в борьбе за право управления государством. Революции в этом случае выступают исключительно как средство борьбы за политический контроль и происходят только благодаря способности оппозиции мобилизовать значительные ресурсы. Основателем и ярким представителем данного направления является Ч. Тилли. Если перефразировать слова К. Клаузевица, революция - это «продолжение политики иными средствами», то есть одна из разновидностей политического процесса. Революция есть заключительная стадия соперничества за политический контроль, который наступает тогда, когда политические группы становятся способны мобилизовать необходимые ресурсы для завоевания власти силовым незаконным путем у старого режима. Данная научная школа предлагает «соревновательную модель революции» [Tilly 1978: 43-51].

Пятая школа во главе с Дж. Голдстоуном определяет главенствующей детерминантой структурный состав общества. Так, в ряде случаев революция произошла в момент, когда доля молодых людей в общей численности населения пре- 
вышала какой-то допустимый уровень - высокая доля «пехоты революции» [Goldstone 1991: 3].

Существует интересное наблюдение: революционные движения наиболее характерны для территорий, находящихся на стыке принципиально отличающихся друг от друга культурно-цивилизационных систем. Именно там вполне отчетливо просматриваются зоны нестабильности, в том числе и вокруг Западной Европы. Так, вполне очевидно выстраивается практически сплошная линия, которая начинается от Гибралтара и далее проходит по Северной Африке вдоль средиземноморского побережья через Ближний Восток к Армении и Грузии, далее через Украину, Белоруссию к бывшим прибалтийским республикам. Достаточно четко прослеживается и линия, проходящая по азиатским республикам бывшего Советского Союза. В то же время мы практически не видим ничего подобного в Северной Америке, в Африке (южнее Сахары), в Австралии, а также, с некоторыми оговорками, в Южной Америке. Аналогичная ситуация на азиатском пространстве (помимо уже упомянутых регионов этого континента), где наблюдаются лишь отдельные очаги подобия «цветных революций», примером чего могут быть события на Филиппинах (1986 г.) или в Гонконге (2014-2015 гг.) [Чумаков 2019: 186-202]. Если рассматривать феномен революций под таким углом зрения, невольно напрашивается вывод о том, что причины следует искать не только в социально-политическом устройстве и экономическом состоянии отдельных стран, но и в том, как они соотносятся с окружающими их общественными системами.

В психологии существует феномен, названный эффектом контраста. Понять его суть можно, лишь описав опыт, с помощью которого он был обнаружен. Двум группам юношей показывали одни и те же фотографии девушек, с которыми предстояло свидание вслепую. Та группа юношей, которая посмотрела перед опытом художественный фильм «Ангелы Чарли» с актрисами модельной внешности, оценивали девушек на фотографии гораздо ниже, чем группа, избежавшая просмотра фильма [Канеман 2013: 81]. Проецируя данную ситуацию на социум, вполне законно предположить появление широкого недовольства действительностью у тех, кто общался с представителями социальных объединений более высокого уровня жизни. Революция 2014 г. в Украине как раз и находилась на «цивилизационном разломе», а предварительный анализ революционной пропаганды показывает высокий процент агитационных материалов, основанных на эффекте контраста, демонстрировавших высокие жизненные стандарты Европейского союза.

Проанализировав революции двух последних десятилетий, ряд исследователей пришли к выводу об ограниченной применимости методологии вышеперечисленных школ в деле объяснения возникновения и протекания революционного процесса, его прогнозирования. Была замечена одна немаловажная особенность, заключающаяся в том, что иногда при совпадении в один непродолжительный период времени всех революционных предпосылок многие страны без титанических усилий избегали потрясений обновления. Однако они часто происходят в странах, которые по показателям угнетения, неравенства, степени политической борьбы в верхах власти и других ключевых показателей находятся не на последних позициях. Это заметил еще А. де Токвиль [2008], указав на революционный взрыв в благополучные для Франции годы. 
Исследователи зачастую обходят стороной еще одну теорию возникновения революционного потенциала, описанную итальянским философом-марксистом А. Грамши. Один из ключевых разделов теории Грамши - учение о гегемонии. Он описал процесс слома старого государства и переход к новому социальнополитическому укладу посредством длительной подспудной идеологической работы по уничтожению старого порядка путем внушения массам идеи необходимости установления порядка качественно нового. Средства его достижения нельзя расценивать как пропаганду. В трудах видных деятелей коммунистической идеологии предпочтение отдается одному пути - от базиса к надстройке, когда экономические отношения определяют все остальные отношения, в том числе и коммуникативные. Грамши описал иной процесс, когда активная атака на надстройку значительно облегчает слом или реформирование самого базиса. Государство, согласно Н. Макиавелли и А. Грамши, держится на силе и согласии. Приемлемый для подавляющего большинства населения уровень согласия о целесообразности сохранения существующего уклада Грамши называет гегемонией. Важно в этом случае иметь в виду и его определение государства: «Государство - это вся совокупность практической и теоретической деятельности, посредством которой господствующий класс оправдывает и удерживает свое господство, добиваясь при этом активного согласия руководимых» [Грамши 1991: 92]. Гегемония опирается на «культурное ядро», которое включает в себя совокупность представлений о мире и человеке, о добре и зле, прекрасном и отвратительном, традициях и предрассудках, знаниях и опыте веков. «Культурное ядро» - это своего рода коллективная воля, и чем она сильнее, тем устойчивее государство. Задача субъекта революционных преобразований - разрушение этой коллективной воли путем ежедневного незаметного, малыми порциями внушения о необходимости слома старой системы. Внушение это осуществляется в основном творческой интеллигенцией. Как показывает практика последних десятилетий и произошедших в этот период революций, наиболее действенным средством разрушения или укрепления гегемонии представляются СМИ (печать, телевидение, особенно Интернет). Опасность нашего времени состоит в том, что эти средства утекают из рук национальных правительств. В Российской Федерации ведется работа по ограничению иностранного влияния на работу СМИ, функционирующих внутри государства. Время покажет, до какой степени эта работа эффективна.

А. Грамши определил путь, следуя которым государство либо укрепляет свою устойчивость, либо ослабевает. По его мнению, правительству следует воздействовать на обыденное сознание населения, повседневные, «маленькие» мысли среднего человека, непрестанно убеждать его в целесообразности сохранять сложившееся положение вещей средствами, которые к политике могут и не относиться, убеждать в объективности причин отставания от более развитых стран, укреплять уверенность в необходимости сохранения существующего уклада. Сделать это можно с помощью художественных произведений, телепередач различной направленности, видеофильмов и др. Особую роль в этом процессе играет творческая интеллигенция как агент революционных преобразований [Там же: 81].

Нередко практика показывает, что исследование какой-либо проблемы будет эффективнее, если выйти за рамки одного научного направления и рассматривать 
еe с междисциплинарных позиций. Так, социология, политология и другие гуманитарные дисциплины все чаще обращаются к психологии, со временем появляется понимание, что законы мышления определяют как поведение отдельного индивида, так и больших сообществ. С 70-х гг. ХХ в. утвердилось мнение, что человек есть существо разумное, прагматичное, здравомыслящее и по большей части принимающее решения взвешенно и обдуманно, реагирующее в подавляющем большинстве случаев на реальные стимулы. Однако исследования последнего времени сильно поколебали эти представления. Был сделан ряд открытий, помогающих понять механизм воздействия субъекта манипуляции и получить представление об усилении или ослаблении гегемонии. От этого в конечном итоге зависит степень готовности общества к революционным изменениям или стремление к сохранению существующего порядка [Гринин 2019: 13-15]. Д. Канеман в своей книге «Думай медленно, решай быстро» рассмотрел ошибки в рассуждениях обывателей, способные в определенных случаях привести их в лагерь протестующих [Канеман 2013]. В настоящее время идет активное изучение процесса психологического воздействия на разные группы населения. При этом СМИ уже сейчас используют каналы данного воздействия очень активно.

Первый и наиболее значимый психологический эффект - эвристика доступности (от англ. availability heuristic), интуитивный процесс, при котором человек оценивает частоту тех или иных событий по легкости, с которой они приходят на ум. Чем легче вспомнить событие из прошлого, тем индивид больше переоценивает количество их в прошлом и вероятность появления подобного события в будущем. Выводы делаются на основе ограниченного количества примеров из прошедших событий. Это значительно упрощает задачу оценки значимости событий, основанных на собственных воспоминаниях. Такой подход в принятии решений является недостаточно объективным. К примеру, исследования показали, что степень оценки индивидом шансов погибнуть в результате террористического акта значительно возрастает после знакомства с информацией о терактах, умереть от инфаркта - после аналогичного случая со знакомым, попасть в ДТП после увиденного своими глазами или через СМИ события. Возможно, эту психологическую особенность имел в виду Джордж Оруэлл в романе «1984», когда писал: «Тот, кто управляет прошлым, управляет будущим. Тот, кто управляет настоящим, управляет прошлым». Средства массовой информации путем многократного представления схожих по тематике материалов имеют возможность изменить оценку вероятности какого-либо события. Согласно теореме Томаса, «если ситуация воспринимается как реальная - она реальна и по своим последствиям». Используя эффект эвристики доступности, скомпоновав определенным образом материал по смысловому содержанию в единое целое, можно изменить оценку вероятности событий объектами манипуляции, заставить объект оценивать ситуацию как реальную. Практика показывает, что материалы, формирующие оценку вероятности события, могут содержать необъективную информацию, откровенный подлог, клевету. Так, перед революцией достаточно демонстрировать очень высокий уровень потребления богача, чтобы объект манипуляции неверно оценил степень имущественной дифференциации в обществе и стал более «революционным». Демонстрируя беззаконие отдельного чиновника, реальное или вымышленное, революционная пропаганда подрывает основы легитимности всего пра- 
вящего класса. Перед революцией, используя эффект эвристики доступности, субъектом пропаганды предпринимаются усилия по двум направлениям: путем многократной демонстрации коррумпированности, слабости правительства снизить уровень легитимности правительства и путем демонстрации положительных примеров из жизни государств, в которых революция свершилась, «легитимизировать» оппозиционные силы. Под воздействием такого рода пропаганды объект манипуляции недооценивает вероятность положительных перемен без революционных преобразований, оценивает вероятность коррумпированности всего чиновничьего аппарата значительно выше и склоняется к необходимости перемен насильственным путем. На вопрос «Все ли чиновники коррумпированы?» ответ «Да» более вероятен, если испытуемый накануне посредством СМИ познакомился с одним или несколькими случаями коррупции среди чиновников. Д. Канеман получил Нобелевскую премию за открытия в области принятия решений в условиях неопределенности, а революционная ситуация как раз и является таковой.

Второй вариант эвристики, приводящий к необъективности суждений, - это эвристика репрезентативности (от англ. representativeness heuristic). Репрезентативность - это мера совпадения свойств, характеристик выборки со свойствами, характеристиками генеральной совокупности. Было проведено немалое количество исследований по вопросу воспроизведения целого по отдельной его части. Был сделан однозначный вывод: если показать испытуемым часть, то остальное они додумают сами, в зависимости от «оттенка» показанной части. Данный эффект применяется субъектом манипуляции, демонстрируя через каналы манипуляции лишь одну сторону объекта. В ходе проведения выборов можно рассказывать лишь о тех характеристиках кандидата, которые обязательно принесут голоса избирателей. В предвыборной борьбе необходимо «выпячивать» положительные стороны своего кандидата и негативные конкурента. В революционной борьбе порочащие эпизоды из жизни политиков в обязательном порядке используются оппозицией в целях дискредитации всего правящего класса. При показе богачей во власти объектами манипуляции однозначно преувеличивается их число. Объект манипуляции видит небольшую часть явления, процесса, движения, коллектива и делает вывод о том, что целое в обязательном порядке имеет сходные качества. У объекта манипуляции имеется природная склонность искать закономерности и тренды там, где их нет.

Третья эвристика, приводящая к ошибкам, называется «корректировка и закрепление» (от англ. Heuristics and Biases). Она открыта в ходе психологических экспериментов с испытуемыми, где они оценивали числовые значения в зависимости от действия на них «якоря» каким-либо образом сообщенной цифры в самом вопросе или непосредственно перед вопросом. Эксперименты показали удивительное стремление испытуемых дать свое числовое значение таким образом, чтобы оно не сильно отличалось от числа-якоря. К примеру, обсуждая с группой долю африканских стран в ООН, экспериментатор спрашивает: «Она больше или меньше $10 \%$ ?». В ходе дискуссии группа пришла к общему мнению, что стран около $25 \%$. В другой группе испытуемых при «якоре» в 65 \% после всеобщего обсуждения сошлись во мнении, что их доля около 45 \%. Данный эффект широко используется при манипуляциях общественным мнением с помощью статистиче- 
ских данных. Как любил шутить Бенджамин Дизраэли, «существует три типа лжи: ложь, наглая ложь и статистика». Используя этот психологический эффект, объекту манипуляции предлагают оценить количественно то или иное явление, предоставив «якорь»; зная стремление смещения значения от «якоря» к середине процентной шкалы, меняют оценку в нужную сторону.

Еще одно обстоятельство требует особого внимания. Д. Канеман экспериментально доказал, что если объект манипуляции придал какому-либо явлению эмоциональную окраску, то он становится наиболее чувствителен к тем фактам, которые соответствуют этой окраске. Одно из направлений деятельности претендующего на власть или другого заинтересованного субъекта - придание негативной эмоциональной окраски действующему правительству в целом и наиболее значимым политическим фигурам. Процесс формирования эмоциональной окраски под воздействием вышеперечисленных эвристик требует отдельного изучения.

В рамках данной статьи не представляется возможным рассмотреть все эвристики, приводящие к ошибкам и заставляющие действовать под влиянием искаженной картины действительности. Однако предварительный анализ показывает, что в предреволюционной стране с помощью эвристики доступности, реперзентативности и якорения наиболее часто создаются агитационные материалы для населения.

В настоящее время особенности протекания революционных процессов недостаточно изучены с позиций влияния на них революционной пропаганды и использования в ней приемов, заставляющих делать искаженные выводы. Исследователь вопросов коммуникаций Г. Почепцов предложил понятие «борьба интерпретационных систем». В соответствии с ним события прошлого, настоящего и будущего не важны сами по себе, но важна их интерпретация [Почепцов 2015: 81]. Накануне революции все заинтересованные политико-идеологические центры одни и те же события трактуют по-разному, а заметные конкурентные преимущества оказываются на стороне того центра, который обладает секретами манипуляции или использует методологию А. Грамши в деле разрушения или укрепления гегемонии.

Русский антрополог Б. Ф. Поршнев предложил эволюционную цепочку: «суггестия - контрсуггестия - контрконтрсуггестия» (от лат. Suggestio - внушение). Проще говоря, суггестия есть манупуляция, контрсуггестия - возникающая через какое-то время способность объекта манипуляции противостоять внушению, заражению чужими чувствами и мыслями, «иммунитет к манипуляции», контрконтрсуггестия - преодоление противостояния прямому внушению, когда субъект вновь обретает ментальную власть над объектом [Поршнев 1965: 114]. Д. Канеман утверждает, что знание об эвристиках снижает эффективность их воздействия на объект манипуляции и ведет к более «правильному» мышлению.

Развитие знаний о способах и методах воздействия субъекта манипуляции это путь минимизации революционных потрясений и залог стабильного существования общества, способного обеспечить процесс государственных преобразований без революционных потрясений. 


\section{Литература}

Аристотель. Политика // Аристотель. Соч.: в 4 т. Т. 4. М. : Мысль, 1983.

Глобализация и современная Россия / под ред. В. Ю. Бельского, А. И. Сацуты. М. : Юнити-Дана, 2014.

Гоббс Т. Философские основания учения о гражданине. Минск : Харвест, 2001.

Грамши А. Тюремные тетради. Часть первая. М. : Политиздат, 1991.

Гринин Л. Е. Взгляд в будущее: прогнозы на XXI столетие // Век глобализации. 2019. № 3(31). С. 3-24.

Дейвис Д. К теории революции // Американское социологическое обозрение. 1967. Вып. 27. № 1. С. 5-12.

Канеман Д. Думай медленно... решай быстро. М. : АСТ, 2013.

Поршнев Б. Ф. Элементы социальной психологии // Проблемы общественной психологии. М. : Наука, 1965. С. 18-34.

Почепцов Г. Г. Информационные войны. Новый инструментарий политики. М. : Алгоритм, 2015.

Скочпол Т. О революции. М. : Прогресс, 2008.

Сорокин П. А. Социология революции. М. : Территория будущего, 2005.

Токвиль А. Старый порядок и революция. СПб. : Алетейя, 2008.

Чумаков А. Н. Глобальный мир: столкновение интересов. М. : Проспект, 2019.

Эйзенштадт Ш. Революция и преобразование обществ: сравнительное изучение цивилизаций. М. : Аспект Пресс, 1999.

Goldstone J. A. Revolution and Rebellion in the Early Modern World. Berkeley : University of California Press, 1991.

Tilly C. From Mobilization to Revolution. Reading, MA : Addison Wesley, 1978. 